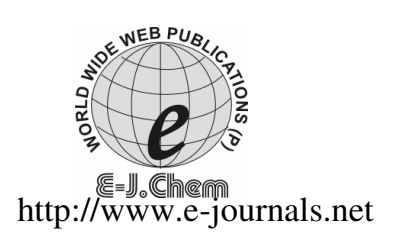

ISSN: 0973-4945; CODEN ECJHAO

E-Journal of Chemistry

2010, 7(4), 1362-1374

\title{
Microwave Enhanced Synthesis of Chitosan-graft- Polyacrylamide Molecularly Imprinted Polymer (MIP) for Selective Extraction of Antioxidants
}

\author{
N. SAIFUDDIN* and A. A. NUR YASUMIRA \\ Chemistry Unit, Department of Engineering Sciences, \\ College of Engineering, Universiti Tenaga Nasional, \\ Km 7, Jalan Kajang-Puchong, 43009 Serdang, Selangor, Malaysia. \\ saifuddin@uniten.edu.my
}

Received 29 January 2010; Accepted 20 March 2010

\begin{abstract}
Polymers have been molecularly imprinted for the purpose of binding specifically to $\alpha$-tocotrienol (vitamin E). A molecularly imprinted polymer (MIP) material was prepared using $\alpha$-tocotrienol as the imprinted molecule, acrylamide as functional monomer and macroporous chitosan beads as functional matrix. Chitosan-graft-polyacrylamide was synthesized without any radical initiator or catalyst using microwave (MW) irradiation. The representative microwave synthesized graft copolymer was characterized by fourier transform-infrared spectroscopy, taking chitosan as a reference. Microwave irradiation was exploited for polyacrylamide grafting on the cross-linked chitosan beads to produce MIP, where both time as well as chemicals can be saved. It can be assumed that the chitosan coated polyacrylamide MIP will have better $\mathrm{pH}$ stability and enhanced adsorption capacity. The maximum adsorption capacity was observed to be 3.95 $\mathrm{mg} / \mathrm{g}$ of MIP, which gave removal efficiency of $93 \%$. After $4 \mathrm{~h}$, the change of adsorption capacities for $\alpha$-tocotrienol did not show notable effects. The Langmuir and Freundlich adsorption models were also applied to describe the equilibrium isotherms.
\end{abstract}

Keywords: Chitosan beads, Molecular imprinting, $\alpha$-Tocotrienol, Palm oil, Microwave.

\section{Introduction}

Antioxidants, such as some vitamins, are physiological substances and play an important role in food due to their ability to deactivate free radicals in organisms. Free radicals may be a danger to cells and their components, if their level of concentration is not controlled. In such a case, cancer and other severe diseases may occur. The control of the radicals is 
realized via the activity of antioxidants like Vitamins $\mathrm{A}, \mathrm{C}$ or $\mathrm{E}^{1}$ which may donate electrons to the radicals. Vitamin $\mathrm{E}$ is one of the most important lipid-soluble primary defence antioxidants. Vitamin $\mathrm{E}$ is a potent antioxidant that protects the body against oxidative damage, notably cell membranes and cholesterol transporting lipoproteins ${ }^{2}$. Vitamin $\mathrm{E}$ is a generic term used for several naturally occurring tocopherols and tocotrienols. The vitamin $\mathrm{E}$ molecule can be divided into two parts, a hydroxyl-bearing aromatic system (one phenolic and one heterocyclic ring, called the chroman head) that is responsible for its antioxidant properties, and either a saturated (tocopherols) or polyunsaturated (tocotrienols) hydrocarbon tail as shown in Figure 1. Naturally occurring vitamin E is widely distributed in nature and is represented by a family of structurally related compounds (vitamers). The eight naturally occurring vitamers are $\alpha$-, $\beta$-, $\gamma$ - and $\delta$-tocopherols (T) and $\alpha-, \beta$-, $\gamma$ - and $\delta$-tocotrienols $\left(\mathrm{T}_{3}\right)$ as shown in Figure 1. The biological activities of vitamin $\mathrm{E}$ in different sources differ significantly with the richest sources of vitamin $\mathrm{E}$ in the diet being vegetable oils and their products. These include wheat germ oil, soybean oil, palm oil, corn oil and cottonseed oil ${ }^{2,3}$. Palm oil contains $600-1000$ ppm of vitamin E. The composition of vitamin E in palm oil is characterized by the presence of $\alpha-\mathrm{T}(20 \%), \alpha-\mathrm{T}_{3}(22 \%), \gamma-\mathrm{T}_{3}(46 \%)$ and $\delta-\mathrm{T}_{3}(12 \%)$. Palm oil is unique among the common vegetable oils in having a high content of tocotrienols ${ }^{4}$.
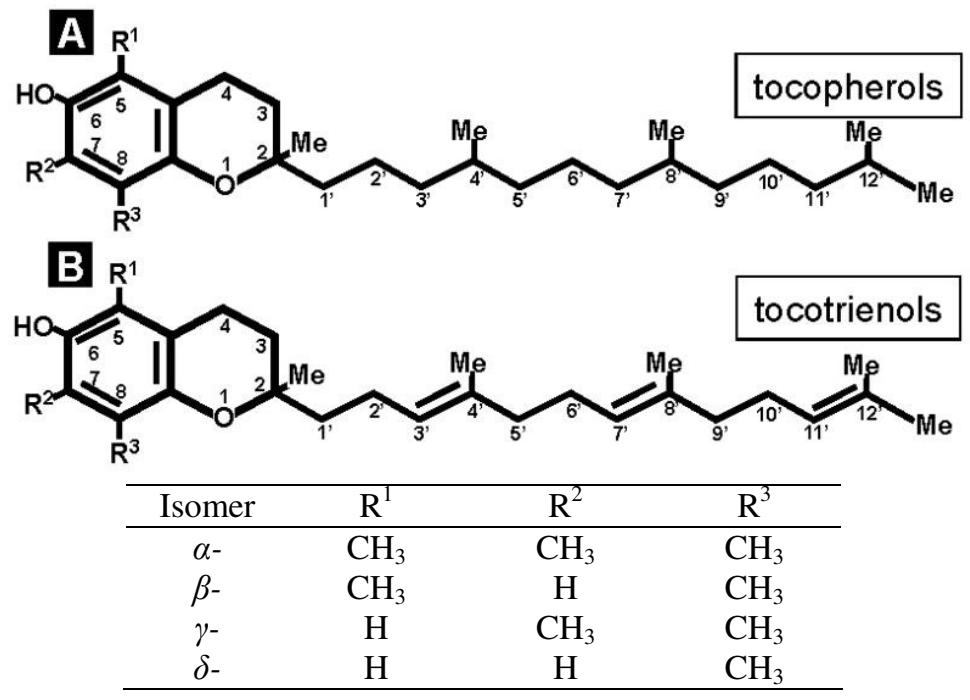

Figure 1. Structures of tocopherol and tocotrienol

Tocopherols and tocotrienols are found abundantly in vegetables, fruits and vegetable oils like palm oil. Because of its high medical importance, it is desirable to develop ways to rapidly and accurately assess the concentrations of vitamin $\mathrm{E}$ in foodstuffs. The gold standard approach for determination of vitamin E relies on chromatographic methods such as high performance liquid chromatography, supercritical fluid chromatography, capillary gas chromatography and thin layer chromatography. The drawback of such approaches is that they are labour-intensive and require tedious sample pre-treatment such as saponification $^{5}$, transesterification ${ }^{6}$, distillation, solvent extraction, membrane separation ${ }^{7}$, crystallization and supercritical $\mathrm{CO}_{2}$ extraction ${ }^{8}$. Owing to their robust properties, MIPs are suitable for broad range of applications as separation media for chromatography ${ }^{9}$, solid phase extraction $^{10}$, recognition elements for biosensors ${ }^{11,12}$, synthetic receptors for peptides ${ }^{13}$ and biological molecules ${ }^{14}$. 
Analytical techniques and tools are used for individual quantitative determinations of vitamins and other antioxidant components. Although for this purpose typical chromatographic or other analytical techniques may be applied, the major bottleneck for the precise and individual analysis of vitamins and antioxidants will be the complex composition of samples derived from the foodstuff. In order to solve this problem, prior to the analysis the antioxidants have to be extracted selectively from the samples, resulting in the requirement of highly selective affinity phases for, e.g., solid phase extraction. Such materials can be manufactured via molecular imprinting. In this paper, we present a simple polymerization method for preparing uniform molecularly imprinted polymer (MIP) beads quickly using microwave promoted grafting of acrylamide (functional monomer) on crosslinked chitosan beads (functional matrix). The produced MIP exhibited higher selectivity and capacity and has good prospects for future application as robust separation matrices for the purification of $\alpha$-tocotrienols.

\section{Experimental}

Chitosan was purchased from Fluka as a flaked material, with a deacetylation percentage of approximately $87 \%$. Glutaraldehyde (GLA), epichlorohydrin (ECH), and ethylene glycol diglycidyl ether (EGDE) purchased from Fluka were analytical-reagent grade. Acrylamide (Merck) and potassium persulfate (BDH, Analar Grade) were used without further purification. All the reagents used were of analytical-reagent grade and used as received. Ultrapure deionized water was obtained using the ELGA Lab Water (UK) water purification system in our laboratory and was used to prepare all the solutions.

\section{Preparation of macroporous chitosan beads}

Chitosan beads were prepared as reported elsewhere with some modification ${ }^{15-17}$. In our work, $3.0 \mathrm{~g}$ chitosan dissolved in $100 \mathrm{~mL}, 2 \%(\mathrm{v} / \mathrm{v})$ acetic acid. The solution was dropped through a seven-gauge needle into $2.0 \mathrm{M}$ sodium hydroxide solution and the gelled spheres formed instantaneously. This process was accomplished by using a model 100 push-pull syringe pump. The formed chitosan beads were kept in the sodium hydroxide solution for $24 \mathrm{~h}$ and washed with distilled water until the washing solution became neutral. After filtering the beads (hereafter called chitosan beads) were stored in distilled water for later use.

\section{Preparation of cross-linked chitosan with microwave irradiation}

Cross-linked chitosan beads were prepared using epichlorohydrin $(\mathrm{ECH})$ as the cross-linking agents following a novel microwave irradiation method modified from the previously mentioned method ${ }^{17,18}$. A solution of $0.04 \mathrm{M}$ epichlorohydrin solution containing $0.067 \mathrm{M}$ sodium hydroxide was prepared $(\mathrm{pH}=10)$. Freshly prepared, $20 \mathrm{~g}$ of wet chitosan beads (using filter to absorb the surface water) were put into a flask with $100 \mathrm{~mL}$ of the epichlorohydrin solution and stirred to allow proper mixing. The mixture was subjected to several (about 12) short burst of microwave irradiation using a microwave oven at frequency of $2.45 \mathrm{GHz}$ at power output of $200 \mathrm{~W}$. Each short burs of irradiation lasted for 1 minute. The mixture was cooled (35-40 seconds at room temperature) between each irradiation. This ramp/cool cycle was repeated 12 times. After the $12^{\text {th }}$ cycle (total time required about 25-30 minutes), the cross-linked beads were filtered and washed extensively with distilled water to remove any unreacted epichlorohydrin until the washing solution became neutral (the neutrality measured by universal indicator paper) and air dried. The diameter of the wet cross-linked bead was approximately $1.75 \pm 0.05 \mathrm{~mm}$. The newly formed cross-linked beads (hereafter called chitosan-ECH beads) obtained were confirmed by a Perkin-Elmer FT-IR System 2000 Model spectrometer. 


\section{Characterization of cross-linked chitosan beads}

The amine content of the cross-linked chitosan beads was determined titrimetrically. Crosslinked chitosan beads $(1.0 \mathrm{~g})$ (filter paper used to absorb the surface water) were added to $0.1 \mathrm{M}$ hydrochloric acid $(20 \mathrm{~mL})$; the mixture was left to stand for $16 \mathrm{~h}$ in a tightly closed bottle. The mixture was filtered and the filtrate $(5 \mathrm{~mL})$ was titrated with a $0.1 \mathrm{M}$ sodium hydroxide. The surface morphology of the wet beads was studied using an environmental scanning electron microscope (ESEM Philips X130). Samples containing water without drying were mounted on metal stubs and at low vacuum degree $\left(\sim 10^{-3} \mathrm{~atm}\right)$ and relatively low temperature (near $0{ }^{\circ} \mathrm{C}$ ) observed.

\section{Dissolution and swelling test of chitosan}

Chitosan and cross-linked chitosan beads were tested with regard to their solubility in each of $5 \%(\mathrm{v} / \mathrm{v})$ acetic acid, distilled water and $0.10 \mathrm{M}$ sodium hydroxide solution by adding $0.10 \mathrm{~g}$ of chitosan and cross-linked chitosan beads in each of the dilute acid, distilled water and dilute alkaline solutions for a period of $24 \mathrm{~h}$ with stirring.

The swelling studies of chitosan and cross-linked chitosan beads were carried out in distilled water at room temperature for a period of $24 \mathrm{~h}$. The percentages of swelling of these beads were calculated by using the following equation (eq. 1):

$$
\text { Percentage of swelling }=\frac{W_{S}-W}{W} \times 100 \%
$$

Where $W_{s}$ is the weight of swollen beads (g) and $W$ is the weight of dry beads $(\mathrm{g})$.

Preparation of $\alpha$-tocotrienol-imprinted polymer by graft copolymerization of acrylamide under microwave irradiation

The preparation of tocotrienol-imprinted polymer was achieved by the combine use of acrylamide as the functional monomer and cross-linked chitosan particles (chitosan-ECH beads) as supporting matrix. The imprinted polymer was prepared by homogeneous chemical graft copolymerization of acrylamide into the porous cross-linked chitosan beads before starting the polymerization. Typically, the template, $\alpha$-tocotrienol $(1 \mathrm{mmol})$ was dissolved in acetonitrile $(30 \mathrm{~mL})$ in a flask. Then $16.0 \mathrm{~g}$ wet chemically-modified crosslinked chitosan beads (as supporting matrix) (use filter to absorb the surface water), $26.5 \mathrm{mmol}$ acrylamide (functional monomer), $1.0 \mathrm{mmol} N, N$ '-methylene-bis-acrylamide (as cross linker) and $40 \mathrm{~mL} 0.01 \mathrm{M}$ sodium dihydrogen phosphate buffer ( $\mathrm{pH}$ 6.8) were added to the flask (four-necked flask equipped with a nitrogen inlet). After degassing and nitrogen purging for 15 minutes, the flask was sealed and the contents were irradiated in microwave oven at frequency of $2.45 \mathrm{GHz}$ at power output of $200 \mathrm{~W}$ for 5 minutes to allow the polymerization to take place. After the polymerization, the formed polyacrylamide-LACC composite beads were freed from the surround polyacrylamide gel by pressing out the surrounding polyacrylamide gel using a nylon stocking. The freed polyacrylamide-LACC beads were wet grained in a ball mill and then sieved to a size between 100 mesh $(10 \mu \mathrm{m})$ and 500 mesh $(2 \mu \mathrm{m})$. The resulting MIP particles were collected by centrifugation. The template molecules were leached out by washing with methanol-acetic acid solution $(3: 1, \mathrm{v} / \mathrm{v})$ four times each at duration of $1.5 \mathrm{~h}$. Then it was followed by ten washings with $15 \mathrm{~mL}$ of methanol at $1 \mathrm{~h}$ for each washing. The particles were then extensively washed with water and dried at $40{ }^{\circ} \mathrm{C}$. The corresponding non-imprinted polymer (NIP) was prepared in parallel in the absence of template and treated in the same manner. 


\section{The morphologies of the MIP beads}

The surface morphologies of the beads were observed using a scanning electron microscope (SEM, model S-3500 N, HITACHT, Japan). The beads were freeze-dried prior to be coated with a gold layer.

\section{Adsorption dynamics of the MIP}

To investigate the adsorption dynamics of the MIP beads, the wet MIP $1.0 \mathrm{~g}$ (using filter to absorb the surface water) was placed in a $50 \mathrm{~mL}$ conical flask and mixed with $25 \mathrm{~mL}$ of $4.0 \times 10^{-4} \mathrm{M}$ of $\alpha$-tocotrienol in absolute ethanol solution. The conical flask was oscillated in a water-bath oscillator with constant temperature at $25{ }^{\circ} \mathrm{C}$ for different time intervals (such as $0.5 \mathrm{~h}, 1.0 \mathrm{~h}, 1.5 \mathrm{~h}, 2.0 \mathrm{~h}, 2.5 \mathrm{~h}, 3.0 \mathrm{~h}, 3.5,4.0,4.5$ and $5 \mathrm{~h}$ ); The concentration of $\alpha$-tocotrienol in the solution was determined using the copper(II)-neocuproine (2,9-dimehyl-1,10phenanthroline) spectrophotometric procedure ${ }^{19}$ at $450 \mathrm{~nm}$. Typically, in a test tube were placed $1.0 \mathrm{~mL}$ of $\mathrm{CuCl}_{2}$ solution $\left(1.0 \times 10^{-2} \mathrm{M} \mathrm{CuCl} \mathrm{Cu}_{2} .2 \mathrm{H}_{2} \mathrm{O}\right), 2.5 \mathrm{~mL}$ of neocuproine solution $\left(3 \times 10^{-3} \mathrm{M}\right.$ in absolute ethanol) $3.0-\mathrm{x} \mathrm{mL}$ ethanol, $1.0 \mathrm{~mL}$ of $1.0 \mathrm{M}$ ammonium acetate buffer, $\mathrm{pH} 7$ and $\mathrm{x} \mathrm{mL}(0.3 \leq \mathrm{x} \leq 0.6 \mathrm{~mL})$ of $\alpha$-tocotrienol solution, in that order. The mixture was agitated and its absorbance was measured after $30 \mathrm{~min}$ at $450 \mathrm{~nm}$ against a reagent blank containing copper(II)-neocuproine, solvent and buffer.

The adsorption capacity $\mathrm{Q}$, was calculated based on the difference of $\alpha$-tocotrienol concentration before and after adsorption, the volume of aqueous solution and the weight of the beads according to equation (2)

$$
\text { Adsorption capacity } \mathrm{Q}=\left(C_{o}-C_{t}\right) \frac{V}{W}
$$

Where $\mathrm{C}_{0}$ is the initial $\alpha$-tocotrienol concentration $(\mathrm{mg} / \mathrm{mL}), \mathrm{C}_{\mathrm{t}}$ is the $\alpha$-tocotrienol concentration $(\mathrm{mg} / \mathrm{mL})$ of different time, $\mathrm{V}$ is the volume of $\alpha$-tocotrienol solution $(\mathrm{mL})$ and $\mathrm{W}$ is the weight of the MIP beads (g).

The adsorption removal efficiency of $\alpha$-tocotrienol from aqueous solution was calculated as follows (eq. 3):

$$
\text { Removal efficiency }(\%)=\frac{C_{o}-C_{f}}{C_{o}} x 100
$$

Where $C_{o}$ is the initial $\alpha$-tocotrienol concentration in the solution and $C_{f}$ is the final $\alpha$-tocotrienol concentration in the solution.

\section{Adsorption isotherm}

The wet MIP beads (1.0 g approximately) (the beads were gently dabbed dry with a filter paper to remove surface water) was placed in a $50 \mathrm{~mL}$ conical flask and mixed with $25 \mathrm{~mL}$ of a known concentration of $\alpha$-tocotrienol solution (increasing the initial concentration of $\alpha$-tocotrienol from 50.0 to $250.0 \mu \mathrm{g} / \mathrm{mL}$ ). The conical flask was oscillated in an oscillator with constant temperature bath at $25{ }^{\circ} \mathrm{C}$ for $4 \mathrm{~h}$. The concentration of $\alpha$-tocotrienol in the solution was determined using the spectrophotometric method at $450 \mathrm{~nm}$ as mentioned above. The amount of adsorption at equilibrium time $t, q_{e}(\mathrm{mg} / \mathrm{g})$, was calculated by (eq. 4$)$ :

$$
q_{e}=\frac{\left(C_{o}-C_{e}\right)}{W} V
$$

Where $C_{o}$ and $C_{e}$ are the liquid-phase concentrations of $\alpha$-tocotrienol at initial and equilibrium time, respectively; $V$ the volume of the solution (L); $W$ is the mass of dry adsorbent (MIP) used (g). 


\section{Results and Discussion}

\section{The characterization of the chitosan beads and cross-linked chitosan beads}

According to the International Union of Pure and Applied Chemistry (IUPAC) classifications, the pores can be divided into macropores $(d>0.05 \mu \mathrm{m})$, mesopores $(2 \mathrm{~nm}<\mathrm{d}<0.05 \mu \mathrm{m})$ and micropores $(d<2 \mathrm{~nm})$. In this study, chitosan beads were prepared by phase inversion. Uniform particle size $(1.75 \pm 0.05 \mathrm{~mm}$ ) (Figure 2$)$ of the macroporous chitosan beads were obtained. As can be seen from Figure 3(a) and (b), pores with different size were observed and the average pore size of the beads were calculated to be $5.4 \mu \mathrm{m}$. The SEM images of cross-linked chitosan-ECH beads after ground and sieved are depicted in Figure 4. It can be seen that there is a significant difference in surface morphology of the two forms of chitosan beads. A striking feature of the chitosan-ECH beads image was that the appearance were noted to have much asperity and to be more coarsely grained, more porous and rough internal structure. This may offer more adsorption sites for adsorbate (acrylamide binding for MIP preparation). In general, the cavities located on the surface of the fine particles are fully accessible. However, those located inside the particles are only partially accessible or inaccessible, depending on the porosities of the corresponding hosts. Site accessibility, mass transport and hydrodynamic properties are significantly improved by producing porous beads ${ }^{20}$. The cross-linked chitosan beads had average pore size of $4.1 \mu \mathrm{m}$. This result also indicates that chitosan has been chemically modified ${ }^{21}$.

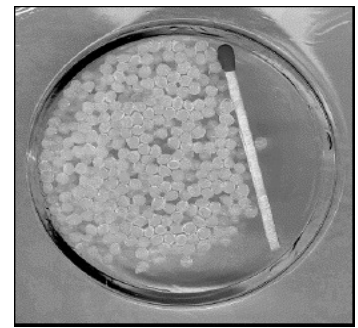

Figure 2. The overall view of chitosan beads

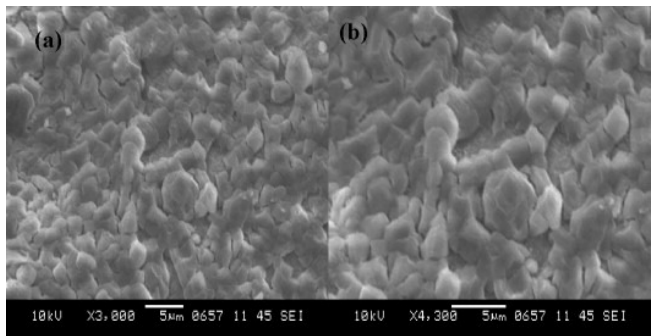

Figure 3. SEM images showing the surface morphologies of the chitosan beads; (a) at $3000 \times$ and (b) $4300 \times$ magnifications

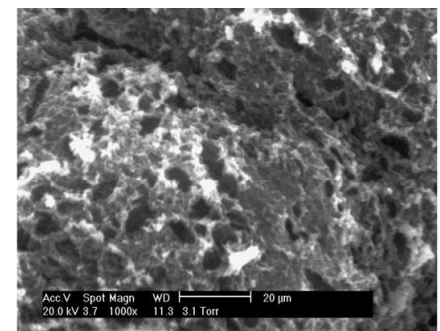

Figure 4. ESEM microphotograph of cross-linked chitosan bead (X 1000) 
Some common cross-linking agents such as glutaraldehyde ${ }^{22}$, epichlorohydrin ${ }^{23}$ and ethylene glycol diglycidyl ether ${ }^{24-26}$ have widely been used in cross-linking of chitosan beads. Epichlorohydrin was selected as a convenient base catalyzed cross-linking agent. The advantage of using ECH as a cross-linking agent is that it does not eliminate the cationic amine function of chitosan, most notably, the cross linking with ECH can considerably improve the wet strength of the chitosan beads ${ }^{25,27}$. An analysis of the cross-linked chitosan beads gave $0.18 \mathrm{mmol}$ of amine content per gram wet beads (the water content was 93.5\%); that means about $18 \%$ amine groups were cross-linked with epichlorhydrin. Obviously, this analytical result indicates that there are enough amine groups in the accessible positions of the cross-linked matrix. The analysis of Chitosan-ECH gave $0.25 \mathrm{mmol}$ of carboxyl content per gram wet beads (water content was $85.3 \%$ ). That means that the vinyl group content was above $0.25 \mathrm{mmol} / \mathrm{g}$ and that most amine had reacted with epichlorohydrin. The reaction of chitosan with epichlorohydrin in an acidic condition might be cross-linked at hydroxyl groups to form the epichlorohydrin cross-linked chitosan product, as shown in Figure 5, which is similar to the scheme that has been reported previously ${ }^{25,27}$.

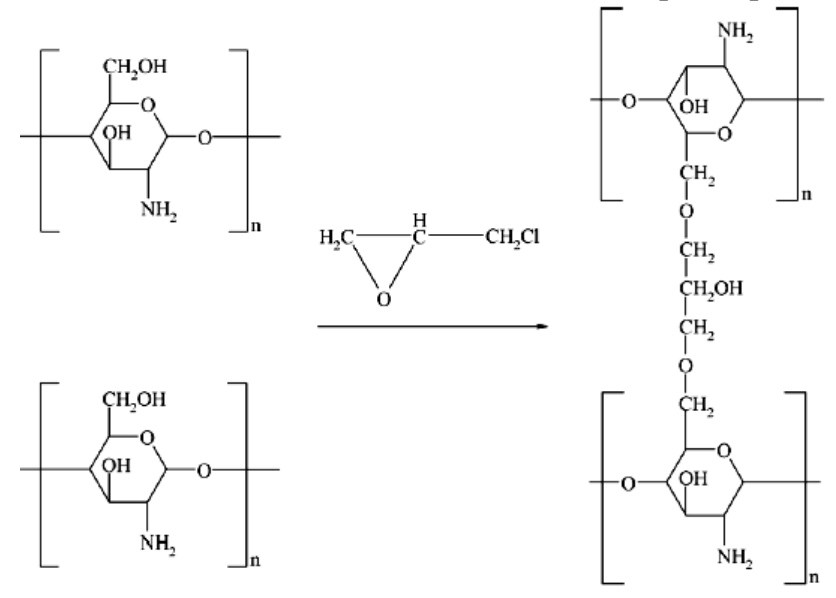

Figure 5. Schematic representation for the cross-linking reaction of chitosan with epichlorohydrin

\section{Solubility and swelling test of chitosan}

It was observed that chitosan beads were soluble in $5 \%$ acetic acid (v/v), but insoluble in both, the distilled water and $0.10 \mathrm{M} \mathrm{NaOH}$ solutions. However after cross linking with epichlorohydrin, the cross-linked chitosan (Chitosan-ECH) was found to be insoluble in acidic and alkaline medium as well as distilled water. It is well known that the high hydrophilicity of chitosan beads or raw chitosan are due to primary amine groups, which makes chitosan easily soluble in dilute acetic or formic acid solutions to yield a hydrogel in water. Therefore, the crosslinking treatment of chitosan reinforces its chemical stability in organic acidic media, making it useful for the removal of chemical pollutants from wastewaters in acidic solution.

The swelling behaviour of chitosan improved after cross-linking. It was observed that chitosan beads had $37.5 \%$ and $32.6 \%$ sweeling when allowed to remain in distilled water and $0.1 \mathrm{M} \mathrm{NaOH}$ solution respectively for $24 \mathrm{~h}$ at room temperature. However the swelling for cross-linked chitosan beads was only $15.3 \%$ in distilled water and $11.8 \%$ in $\mathrm{NaOH}$ under similar conditions. Hence, the change in the swelling percentages between chitosan beads and cross-linked chitosan beads gives a preliminary indication that cross- linking enhances the physical strength of the chitosan beads. From the results obtained, cross-linking modification 
is not only able to increase the surface area and reinforce the chemical strength of the chitosan beads but also reduces the swelling of the beads. Thus, cross-linking treatment increases the rigidity and also the chemical stability of the beads. It is interesting to note that, the less swelling behaviour of cross-linked chitosan beads is important in order for it to be used in an adsorption column.

\section{Infra red spectra of chitosan derivatives}

The characteristic IR absorption peaks of chitosan were observed (Figure 6a), which included a broad and strong band ranging from $3200-3700 \mathrm{~cm}^{-1}$ (stretching vibration of $\mathrm{O}-\mathrm{H}$ and extension vibration of $\mathrm{N}-\mathrm{H}$ ). The peaks located at 2920 and $2869 \mathrm{~cm}^{-1}$ can be assigned to asymmetric and symmetric $-\mathrm{CH}_{2}$ groups. The peak located at 1652 is characteristic of amine deformation. The prominent peak at observed at $1375 \mathrm{~cm}^{-1}$ represents $\mathrm{C}-\mathrm{N}$ stretching. The peak at $1258 \mathrm{~cm}^{-1}$ can be attributed to the $\mathrm{C}-\mathrm{O}-\mathrm{C}$ stretching. The peak at $1082 \mathrm{~cm}^{-1}$ is characteristics of $\mathrm{C}-\mathrm{O}$ stretching vibration. The absorption band at $900 \mathrm{~cm}^{-1}$, corresponds to the characteristic absorption of $\beta-D-$ glucose unit. The infrared spectrum of epichlorohydrin cross-linked chitosan was rather similar to that of chitosan (Figure 6b), since the functional groups of epichlorohydrin were also present in chitosan. Therefore, the same vibrations were observed but with different relative intensities. The absorption intensity of $-\mathrm{NH}_{2}$ group and $-\mathrm{OH}$ group (peak $3200-3700 \mathrm{~cm}^{-1}$ ) from crosslinked chitosan is obviously lower than that of $-\mathrm{NH}_{2}$ group and $-\mathrm{OH}$ group from chitosan, which indicates cross-linked reaction occurred between chitosan and epichlorohydrin. Moreover, the reduction in the intensities at $1418 \mathrm{~cm}^{-1}$ peak (primary amino group, $-\mathrm{NH}_{2}$ ) showed that most of the primary amino groups were involved in the cross-linking process.

Graft copolymer based on chitosan has been synthesized by grafting acrylamide onto modified chitosan (polysaccharide molecule) in aqueous medium using microwave irradiation. The grafting was confirmed by comparing the IR spectra of cross-linked chitosan (Figure $6 \mathrm{~b}$ ) with that of the grafted product (Figure 7). The IR spectrum of the cross-linked chitosan has strong peak around $3441 \mathrm{~cm}^{-1}$ due to the stretching vibration of $\mathrm{O}-\mathrm{H}$, the extension vibration of $\mathrm{N}-\mathrm{H}$ and inter hydrogen bonds of the polysaccharide. In graft copolymer the strong peak around $3400 \mathrm{~cm}^{-1}$ could be assigned to the stretching vibration of $\mathrm{O}-\mathrm{H}$, the extension vibration of $\mathrm{N}-\mathrm{H}$ and inter hydrogen bonds of the polysaccharide (Figure 7). The IR spectrum of a polyacrylamide grafted cross-linked chitosan (Figure 7) has additional sharp absorption peaks at 1731 and $2966 \mathrm{~cm}^{-1}$ (due to carbonyl stretching and symmetrical stretching of the methyl group, respectively). Peak around $1432 \mathrm{~cm}^{-1}$ due to $\mathrm{C}-\mathrm{N}$ stretching in graft copolymer further supports grafting. This result provides a substantial evidence of grafting of polyacrylamide on to the cross-linked chitosan.

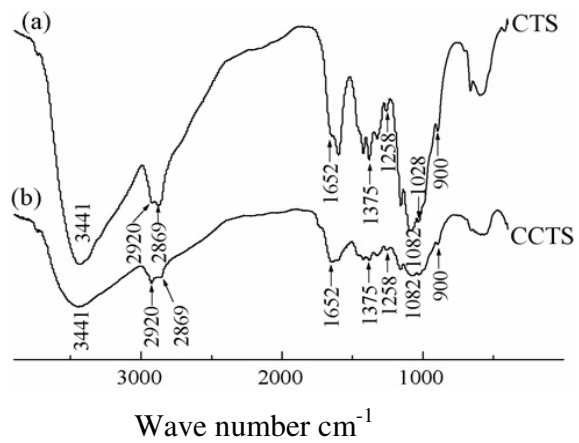

Figure 6. FT-IR spectra (a) Chitosan (labelled as CTS) and (b) epichlorohydrine cross-linked chitosan (labelled as CCTS), using $\mathrm{KBr}$ pellets. The range from 4000 to $400 \mathrm{~cm}^{-1}$ was scanned 


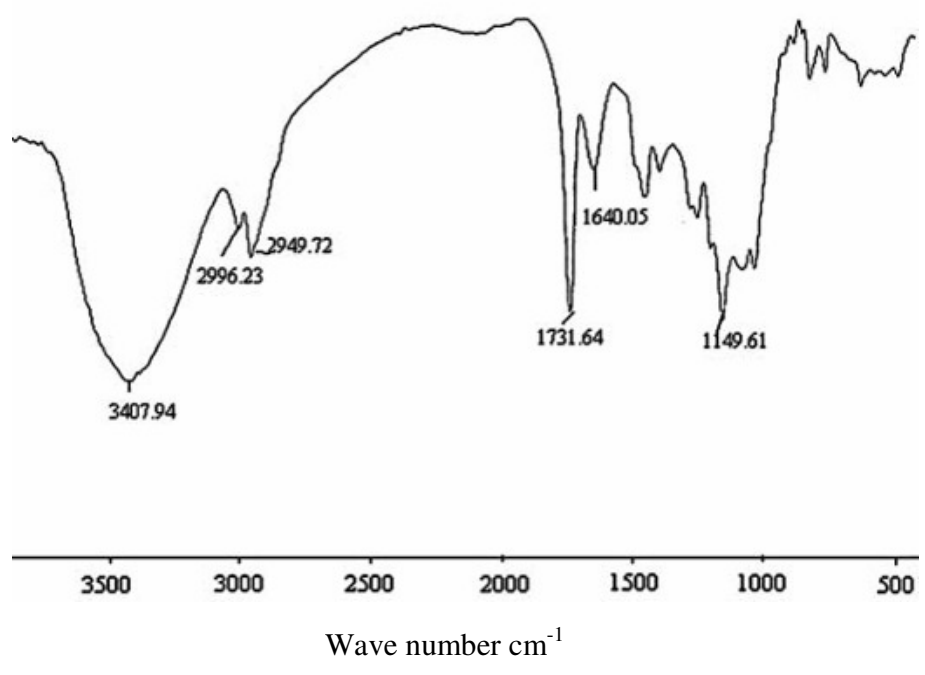

Figure 7. IR spectra of microwave synthesized grafted polyacrylamide-cross-linked chitosan beads

Singh and co-workers reported grafting of grafting of acrylamide 28 and methyl methacrylate ${ }^{29}$ onto chitosan using microwave irradiation. They have shown that under microwave irradiation, grafting could be achieved in the absence of this initiating system (potassium persulfate and ascorbic acid), whereas control experiments with thermal heating at $100{ }^{\circ} \mathrm{C}$ without initiator did not show any grafting, indicating the presence of non-thermal microwave effects. Grafting of both acrylamide and methyl methacrylate was demonstrated to improve the solubility of the chitosan at neutral $\mathrm{pH}$. Moreover, these grafted copolymers showed increased zinc(II) binding (methyl methacrylate and acrylamide) and/or calcium(II) binding (acrylamide) making them suitable candidates for the removal of these ions from waste water ${ }^{29}$. Thus microwave can be exploited for polyacrylamide grafting on the cross-linked chitosan beads to produce MIP, where both time as well as chemicals can be saved. It can be assumed that the chitosan coated polyacrylamide MIP should have better $\mathrm{pH}$ stability and enhanced adsorption capacity.

\section{Dynamic adsorption of $\alpha$-tocotrienol on cross-linked chitosan-polyacrylamide MIP}

The Figure 8 shows the rate of adsorption of $\alpha$-tocotrienol by MIP measured as function of time. The adsorption capacity $\mathrm{Q}$, was calculated based on the difference of $\alpha$-tocotrienol concentration before and after adsorption, the volume of aqueous solution and the weight of the beads according to equation (2)

$$
\text { Adsorption capacity } Q=\left(C_{o}-C_{t}\right) \frac{V}{W}
$$

The figure shows that the amount of $\alpha$-tocotrienol adsorbed from aqueous solution increased with time and equilibrium being achieved within $4 \mathrm{~h}$. The maximum adsorption capacity was observed to be $3.95 \mathrm{mg} / \mathrm{g}$ of MIP, which gave removal efficiency of $93 \%$. After $4 \mathrm{~h}$, the change of adsorption capacities for $\alpha$-tocotrienol did not show notable effects. As a consequence, the adsorption equilibrium time considered for the further work has been taken as $4 \mathrm{~h}$. 


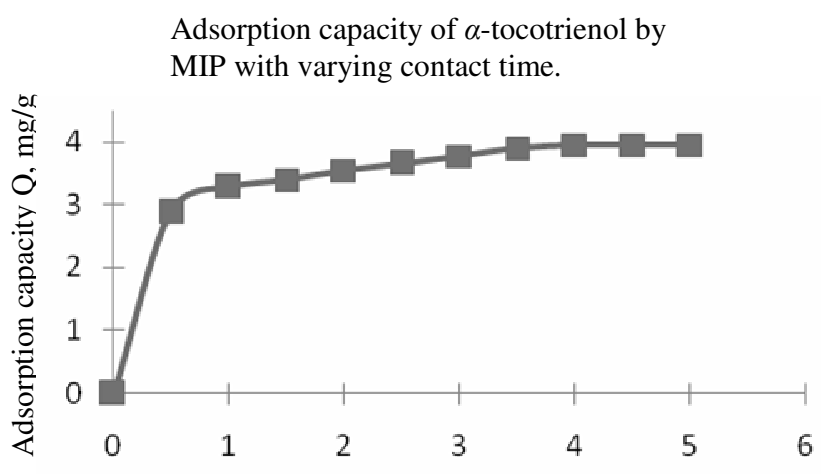

Time, $\mathrm{h}$

Figure 8. Adsorption dynamics of $\alpha$-tocotrienol on the cross-linked chitosan-polyacylamide MIP beads. $\mathrm{V}$ of analyte $=25 \mathrm{~mL}$; Concentration of analyte $=0.170 \mathrm{mg} / \mathrm{mL}$; MIP quantity $=1.0 \mathrm{~g} ; \mathrm{T}=25^{\circ} \mathrm{C}$

\section{Adsorption isotherm}

The adsorption isotherm is the most important information, which indicates how the adsorbent molecules distribute between the liquid and the solid phase when the adsorption process reaches an equilibrium state ${ }^{23}$. The adsorption experiments were conducted in a series of $\alpha$-tocotrienol solutions ( $25 \mathrm{~mL}$ ) with different initial concentrations. The adsorption capacity of $\alpha$-tocotrienol increased from 1.12 to $4.15 \mathrm{mg} / \mathrm{g}$ by increasing the initial concentration of $\alpha$-tocotrienol from $50 \mu \mathrm{g}$ to $300 \mu \mathrm{g} / \mathrm{mL}$ (Figure 9).

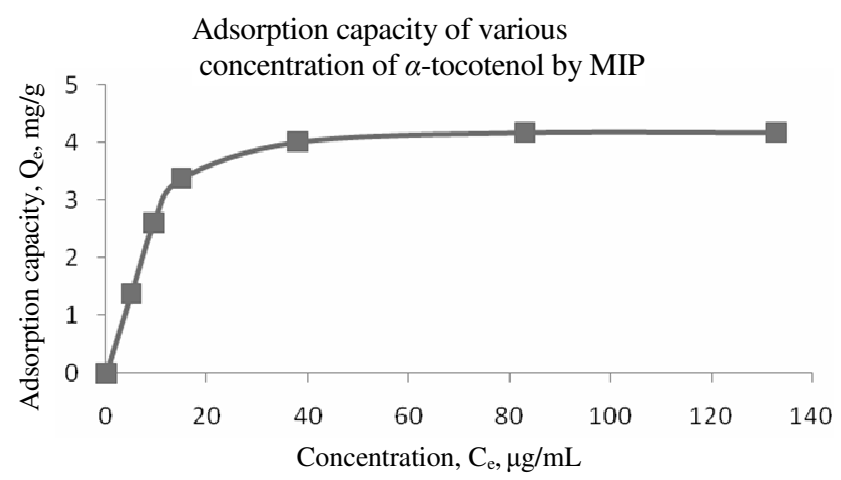

Figure 9. Adsorption isotherms of $\alpha$-tocotrienol on the cross-linked chitosan-polyacylamide MIP beads. Volume of analyte $=25 \mathrm{~mL}$; Concentration of analyte $=50-300 \mu \mathrm{g} / \mathrm{mL}$; MIP quantity: $1.0 \mathrm{~g} ; \mathrm{T}=25^{\circ} \mathrm{C}$; adsorption time $=4 \mathrm{~h}$

The Langmuir and Freundlich models are often used to describe equilibrium adsorption isotherms. The Langmuir isotherm considers the adsorbent surface as homogeneous and all adsorption sites equivalent. There is no interaction between adsorbed molecules and at the maximum adsorption, only a monolayer of adsorbate is formed on the surface of the adsorbent. Eq. (5) represents the Langmuir isotherm:

$$
\frac{C_{e}}{q_{e}}=\frac{C_{e}}{Q}+\frac{1}{Q_{b}}
$$


Where $\mathrm{Q}$ is the maximum adsorption at monolayer $(\mathrm{mg} / \mathrm{g}), \mathrm{C}_{\mathrm{e}}$ is the equilibrium concentration of $\alpha$-tocotrienol $(\mu \mathrm{g} / \mathrm{mL}), \mathrm{q}_{\mathrm{e}}$ is the amount of $\alpha$-tocotrienol adsorbed per unit weight of the MIP at equilibrium concentration $(\mathrm{mg} / \mathrm{g})$ and $\mathrm{b}$ is the Langmuir constant related to the affinity of binding sites $(\mathrm{mL} / \mathrm{mg})$ and is a measure of the energy of adsorption. A linearized plot of $C_{e} / q_{e}$ against $C_{e}$ gives $Q$ and $b$. The plot of specific sorption, Ce/qe, against the equilibrium concentration, Ce, for MIP is shown in Figure 10.

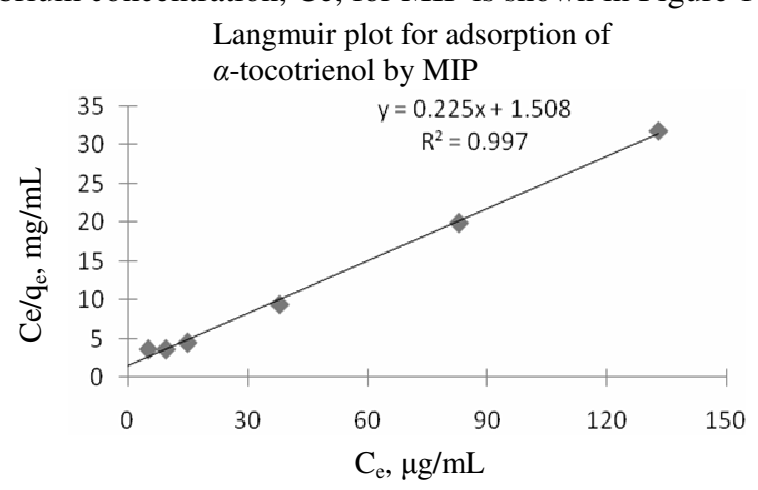

Figure 10. Adsorption isotherms of $\alpha$-tocotrienol cross-linked chitosan-polyacrylamide MIP beads, linearized according to the Langmuir equation

The empirical Freundlich equation (eq. 6) based on adsorption on a heterogeneous surface is given as follows ${ }^{30}$ :

$$
q_{e}=K_{p} x C_{e}{ }^{1 / n}
$$

This expression can be linearized to give (eq. 7):

$$
\ln q_{e}=\ln K_{p}+\frac{1}{n} \ln C_{e}
$$

Where $K_{F}$ and $n$ are the Freundlich constants, which represent adsorption capacity and adsorption intensity, respectively. $K_{F}$ and $n$ can be determined from a linear plot of $\ln q_{e}$ against $\ln C_{e}$. The calculated results of the Langmuir and Freundlich isotherm constants are given in Table 1. Compared to Freundlich, the Langmuir plots have a higher correlation coefficient of 0.9973 . It can be confirmed that $\alpha$-tocotrienol adsorption by MIP follow the Langmuir Model with a maximum adsorption capacity of $4.17 \mathrm{mg} / \mathrm{g}$ at $25^{\circ} \mathrm{C}$ under the range studied.

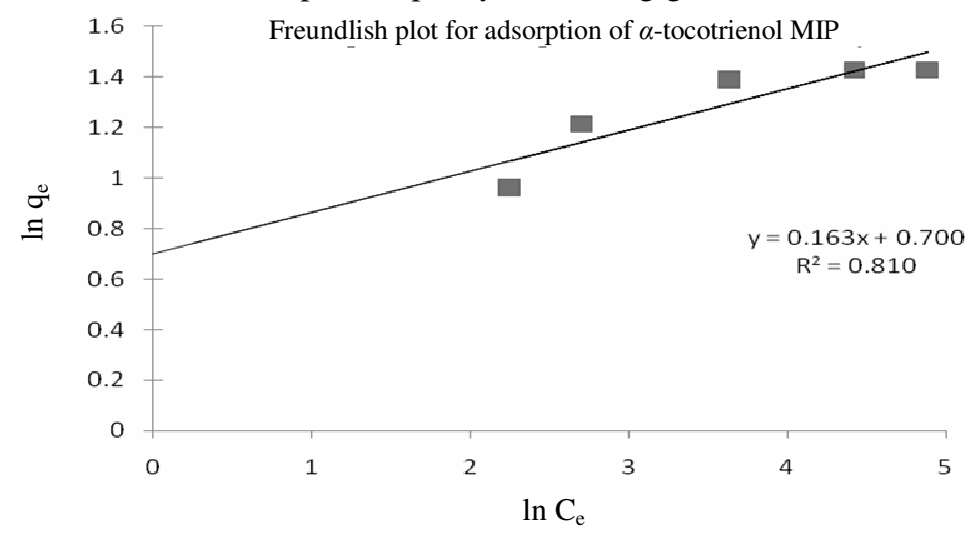

Figure 11. Adsorption isotherms of $\alpha$-tocotrienol cross-linked chitosan-polyacrylamide MIP beads, plotted according to the Freundlich equation 
Table 1. Langmuir and Freundlich isotherm model constants and correlation coefficient

\begin{tabular}{cccccc}
\hline \multicolumn{3}{c}{ Langmuir Isotherm } & \multicolumn{3}{c}{ Freundlich Isotherm } \\
\hline $\begin{array}{c}B \\
(\mathrm{mg} / \mathrm{g})\end{array}$ & $\begin{array}{c}\mathrm{L} / \mathrm{mg}) \\
4.44\end{array}$ & $\mathrm{R}^{2}$ & $\begin{array}{c}\mathrm{K}_{f} \\
(\mathrm{mg} / \mathrm{g})\end{array}$ & $n$ & $\mathrm{R}^{2}$ \\
\hline
\end{tabular}

The essential characteristics of the Langmuir isotherm can be expressed in terms of dimensionless constant separation factor, $R_{L}$ which is used to predict if an adsorption system is 'favourable' or 'unfavourable'. The separation factor, $R_{L}$ is given by (eq. 8$)^{30}$ :

$$
R_{L}=\frac{1}{1+b C_{o}}
$$

Where, $C_{0}$ is the initial $\alpha$-tocotrienol concentration $(\mathrm{mg} / \mathrm{L})$ and $b$ is the Langmuir adsorption constant $(\mathrm{L} / \mathrm{mg})$. Table 2 lists the calculated results. Based on the effect of separation factor on isotherm shape, the $R_{L}$ values are in the range of $0<R_{L}<1$, which indicates that the adsorption of $\alpha$-tocotrienol on crosslinked chitosan-polyacrylamide MIP beads are favourable ${ }^{30}$. Thus, this MIP is favourable adsorbent.

Table 2. $\mathrm{R}_{\mathrm{L}}$ values based on the Langmuir equation

\begin{tabular}{cc}
\hline $\begin{array}{c}\text { Initial } \alpha \text {-tocotrienol } \\
\text { concentration, } \mathrm{mg} / \mathrm{L}\end{array}$ & $\mathrm{R}_{\mathrm{L}}$ value \\
\hline 50 & 0.1182 \\
100 & 0.0628 \\
150 & 0.0428 \\
200 & 0.0324 \\
250 & 0.0261 \\
300 & 0.0218 \\
\hline
\end{tabular}

\section{Conclusions}

The potential use of a molecular imprinted polymer prepared from acrylamide as functional monomer for the effective extraction of $\alpha$-tocotrienol was investigated. It was shown that the rate of adsorption $\alpha$-tocotrienol increased rapidly in the initial stage and then reduced until it reached equilibrium. The adsorption capacity of $\alpha$-tocotrienol increased with increasing concentration of $\alpha$-tocotrienol and the maximum adsorption was $3.95 \mathrm{mg} / \mathrm{g}$ of the MIP beads.

The results showed that the adsorption process obeys a Langmuir adsorption isotherm. Important aspects of this work include the use of macroporous chitosan beads as functional matrix to offer functional groups and bead shape for the imprinted polymer. The prepared imprinted beads exhibit good characteristics, such as fast adsorption dynamics and high adsorption capacity. The fabricated MIP has potential use in a pre-concentration process in trace analysis of and also in development of stationary phase in liquid chromatography columns. Furthermore the MIP developed from cross-linked chitosan-polyacrylamide is inexpensive, non-toxic and easy to prepare.

\section{Acknowledgments}

The author would like to acknowledge the Ministry of Science, Technology and Innovation of Malaysia for funding this research through research grant Science Fund 03-02-03-SF0105 and studentship to one of the author. 


\section{References}

1. Gutteridge J M and Halliwell B, Free Radic Res Commun., 1993, 19, 141-158.

2. Kamal-Eldin A and Appelqvist L A, Lipids, 1996, 31, 671-701.

3. Bramley P M, Elmadfa I, Kafatos A, Kelly F J, Manios Y, Roxborough H E, Schuch W, Sheehy P J A. and Wagner, K-H, Vitamin E, J Sci Food Agric., 2000, 80, 913-938.

4. Goh S H, Choo Y M and Ong S H, J Am Oil Chem Soc., 1985, 62, 237-240.

5. Nagao T, Kobayashi T, Hirota Y, Kitano M, Kishimoto N, Fujita T, Watanabe Y, Shimada Y, J Mol Catal B Enzym., 2005, 37, 56-62.

6. Martins P F, Batistella C B, Maciel-Filho R and Wolf-Maciel M R, Ind Eng Chem Res., 2006, 45, 753-758.

7. Nagesha G K, Subramanian R and Udaya Sankar K, J Am Oil Chem Soc., 2003, 80, 397-402.

8. $\quad$ King J W, Favati F and Taylor S L, Separ Sci Technol., 1996, 31, 1843-1857.

9. Turiel E; Tadeo J L and Cormack P A G, Martin-Esteban A, Analyst, 2005, 130, 1601-1607.

10. Haginaka J, Anal Bioanal Chem., 2004, 379, 332-334.

11. Piacham T, Josell Å, Arwin H, Prachayasittikul V and Ye L, Anal Chim Acta., 2005, 536, 191-196.

12. Hillberg A L, Brain K R and Allender C J, Adv Drug Deliver Rev., 2005, 57, 1875-1889.

13. Hart B R and Shea K J, J Am Chem Soc., 2001, 123, 2072-2073.

14. Boonpangrak S, Prachayasittikul V, Bülow L and Ye L, J Appl Polym Sci., 2006, 99, 1390-1398.

15. Chandy T and Sharma C P, Biomaterials, 1993, 14, 939-944.

16. Shu X Z and Zhu K J, Journal of Microencapsulation, 2001, 18, 237-245.

17. Wei Y C, Hudson S M, Mayer J M and Kaplan D C, J Polym Sci Part A: Polym Chem., 1992, 30, 2187-2193

18. Guo T Y, Xia Y Q, Hao G J, Song M D aand Zhang B H, Biomaterial, 2004, 25, 5905-5912.

19. Tutem E, Apak R, Gunaydi E and Sozgen K, Talanta, 1997, 44, 249-255.

20. Dai S, Zhang Z and Liang C, Hierarchically imprinted nanostructures for separation of metal ions, in: Schwarz J A, Contescu C I and Putyera K, (Eds.), Dekker Encyclopedia of Nanoscience and Nanotechnology, CRC Press, 2004.

21. Kamari A, Wan Ngah W S Chong M Y and Cheah M L, Desalination, 2009, 249, 1180-1189.

22. Cestari A R, Vieira E F S, Tavares A M G and Bruns R E, J Hazard Mater., 2008, 153, 566-574.

23. Hasan M, Ahmad A L, Hameed B H, Chem Eng J., 2008, 136, 164-172.

24. Li N and Bai R, Sep Purif Technol., 2005, 42, 237-247.

25. WanNgah W S, Endud C S and Mayanar R, Funct Polym., 2002, 50 181-190.

26. Wan Ngah W S, Ab Ghani S and Kamari A, Bioresource Technology, 2005, 96, 443-450.

27. Lee S H, Park S Y and Choi J H, J Appl Polym Sci., 2004, 92 2054-2062.

28. Singh V, Tiwari A, Tripathi D N and Sanghi R, Polymer, 2006, 47, 254-260.

29. Singh V, Tiwari A, Tripathi D N and Sanghi R, Polymers, 2006, 65, 35-41.

30. Bhatnagar A and Jain A K, J Colloid Interface Sci., 2005, 28(1), 49-55. 


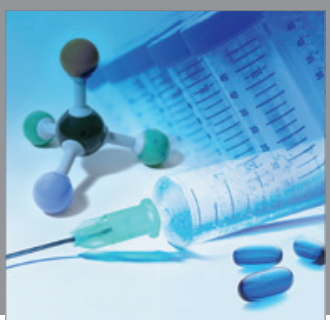

International Journal of

Medicinal Chemistry

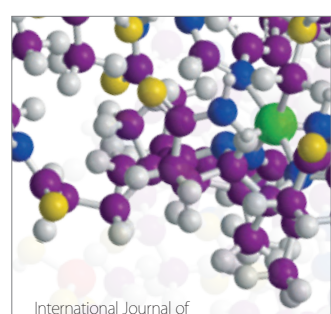

Carbohydrate Chemistry

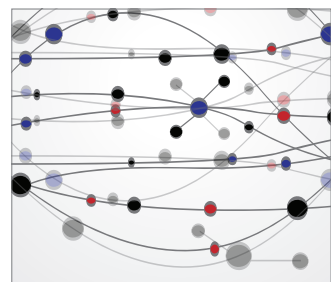

The Scientific World Journal
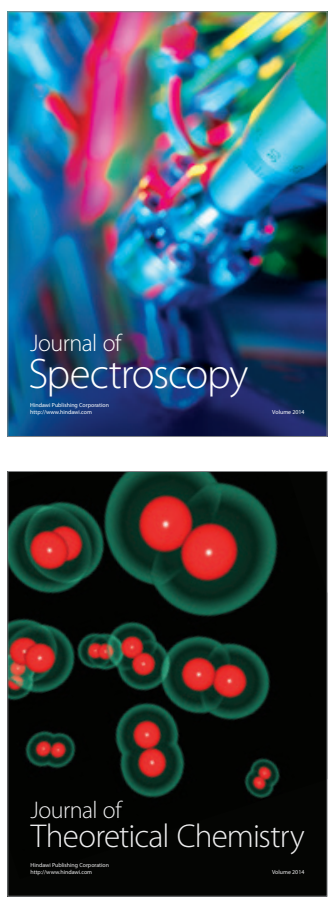
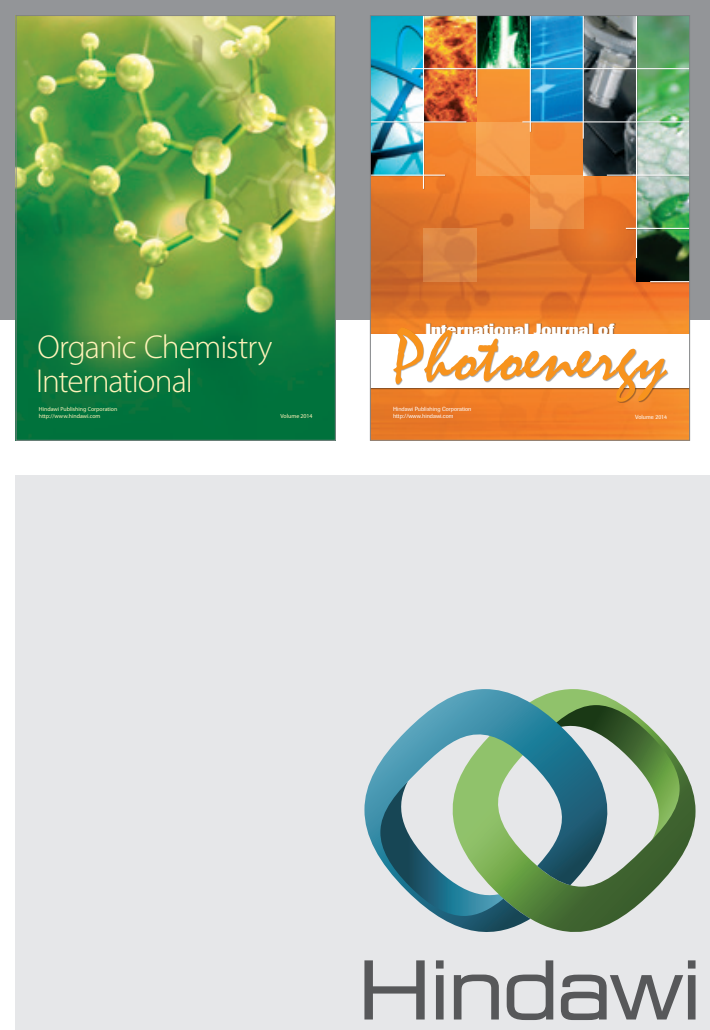

Submit your manuscripts at

http://www.hindawi.com
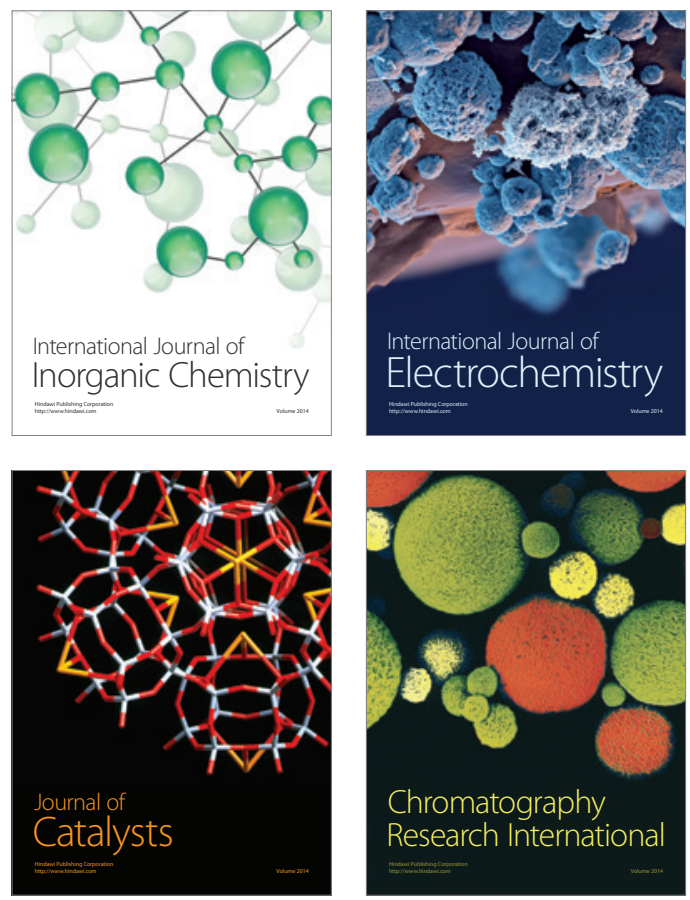
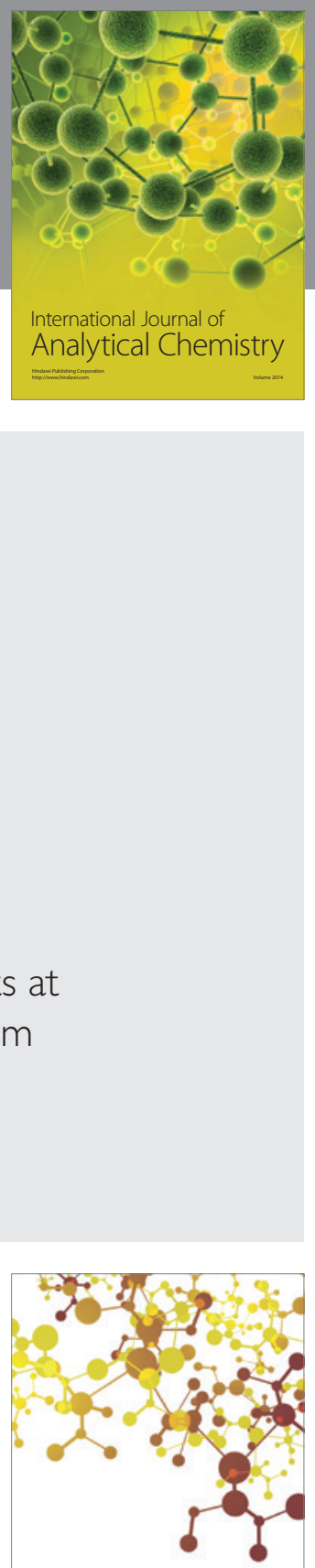

Journal of

Applied Chemistry
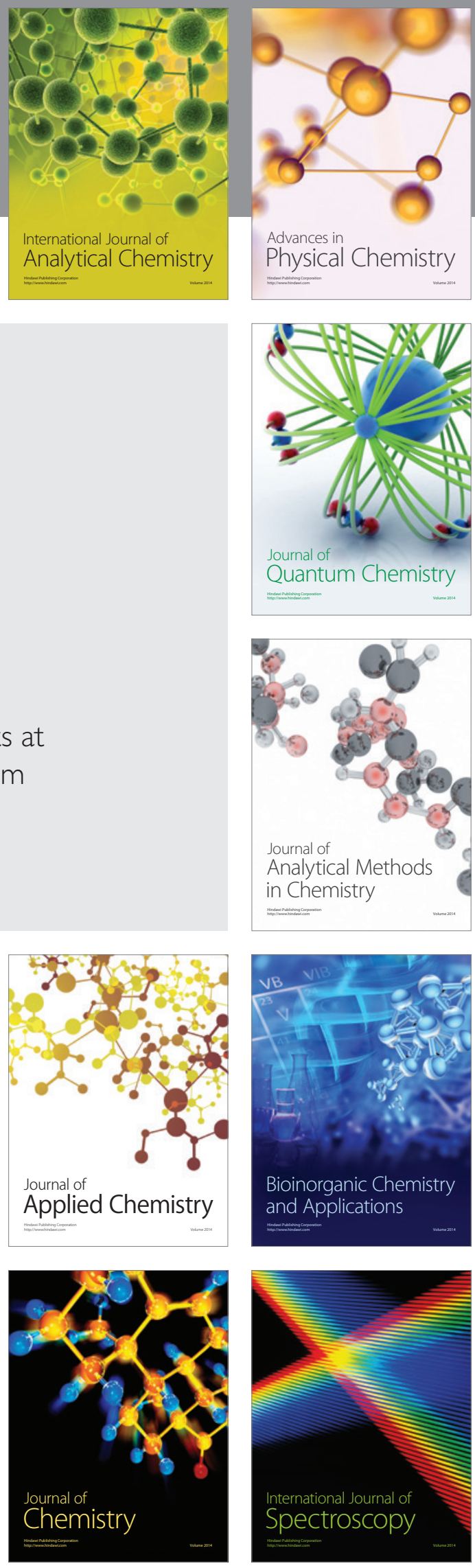